\title{
ENTRE A PRESENÇA E A AUSÊNCIA: \\ A JUSTIÇA SEGUNDO OS TRABALHADORES DE UM BAIRRO PERIFÉRICO
}

\section{Hermes da Fonseca}

Mestrando em Direito (área de concentração Filosofia e Teoria Geral do Direito) pela Universidade Federal de Santa Catarina (UFSC) e bolsista da CAPES.

RESUMO: O texto aborda as representações que os moradores de um bairro periférico da cidade de Franca/SP têm da justiça estatal em seu segmento trabalhista. A primeira parte da exposição contextualiza a temática na realidade brasileira atual, passando em seguida à consideração da especificidade estudada. Estudo teórico-prático, o texto se insere nas discussões sobre os obstáculos ao acesso à Justiça (em sentido não só institucional, mas principalmente axiológico), cingindo-se aos empecilhos de natureza social e cultural, parcamente estudados em nosso país, onde se tem priorizado os estudo das barreiras de natureza econômica. Embora esses obstáculos se encontrem inter-relacionados, será priorizado o aspecto sócio-cultural de uma comunidade urbana periférica.

PALAVRAS-CHAVE: Acesso à justiça - História oral - Justiça do trabalho trabalhadores - Franca. 


\section{INTRODUÇÃO}

Contemplando a questão dos obstáculos sociais e culturais ao acesso à Justiça, especialmente as representações sociais de trabalhadores (desempregados ou sub-empregados) da periferia de uma cidade industrial do interior de São Paulo (Franca) sobre a justiça trabalhista e os direitos formalmente assegurados em tal área, este texto busca relacionar o amplo contexto dessa problemática na sociedade brasileira atual à especificidade da Vila Gosuen - bairro periférico de Franca, um dos maiores pólos exportadores de calçados do país -, espaço da nossa pesquisa.

Assim delimitado o objeto da discussão a ser feita neste texto, alguns problemas ficam, desde logo, evidentes: Por que focalizar o estudo na relação de uma determinada população com a justiça do trabalho? Por que estudar os obstáculos sócio-culturais ao acesso à Justiça? Por que tomar como sujeitos da pesquisa trabalhadores de um bairro pobre? Por que estabelecer a análise a partir das representações sociais dos trabalhadores? Como inserir uma reflexão desta espécie no contexto geral da pesquisa jurídica? Quais as possibilidades de uma relação entre a sociabilidade local (onde a pesquisa se realiza) e a totalidade da sociedade brasileira? São estas algumas das questões a que procuraremos fornecer algumas respostas.

Tomar as possíveis relações dos trabalhadores com a justiça do trabalho, sob a ótica daqueles, pode sugerir uma visão parcial do problema, pouco relevante para a sua compreensão geral. Apesar da explícita referência a uma seção específica da justiça oficial, desde já afirmamos que não partilhamos de uma compreensão monista do fenômeno jurídico, segundo a qual o Estado seria a única fonte produtora e aplicadora das normas jurídicas; tampouco reduzimos o entendimento do acesso à Justiça ao sentido institucional do mero acesso ao Judiciário. Se deixamos de contemplar as representações dos profissionais da justiça trabalhista acerca dos trabalhadores (de forma geral, e não apenas os que litigam), tal postura encontra justificativa na necessidade de um recorte do tema proposto, bem como no predomínio que os pesquisadores da área jurídica têm dispensado ao ambiente interno aos fóruns e tribunais. 
Ao escolhermos as representações da justiça trabalhista tidas por trabalhadores, intentamos questionar o grau de relevância das relações de trabalho no Brasil contemporâneo - a possível centralidade do trabalho na sociedade brasileira. Mesmo não ignorando ser a "justiça trabalhista" uma forma de manifestação da divisão social do trabalho, e que esse setor da justiça oficial apresenta vários pontos comuns às outras seções judiciais, no cerne da nossa problematização está a percepção que os trabalhadores têm de si nas relações (ou ausência de relações) com a justiça trabalhista, quando está em curso um processo em que

"a diluição da identidade do trabalhador na figura do excluído e a ampliação da categoria dos marginalizados produziram e estão produzindo uma mudança social que [...] sobrepõe o excluído ao trabalhador porque, sociologicamente, o trabalhador perde a sua visibilidade como tal. Os protagonistas da situação social adversa que mais golpeia a consciência das elites, e da classe média que delas faz parte, não está mais majoritariamente nas fábricas estão nas ruas, nas favelas e cortiços, nas invasões, nos bairros miseráveis da urbanização patológica que o novo desenvolvimento econômico produziu. [...] Quando muito são trabalhadores dos setores secundários e irrelevantes da produção. Por isso são excluídos. Não só nem principalmente excluídos das oportunidades de participação social. Mas, excluídos das possibilidades ativas de fazer História."1

O protagonismo histórico do operariado e a conseqüente centralidade do trabalho são, então, questionados no específico contexto do processo de mundialização, quando os argumentos hegemônicos levam a crer que o capital se reproduz independentemente do trabalho. Ao formularmos nossa análise nos limites das representações que os trabalhadores de uma determinado espaço urbano têm da justiça trabalhista, os elementos sócio-culturais sobrelevam-se em importância: só são possíveis as representações pela mediação ${ }^{2}$ do vivido, pela compreensão das relações com os outros e da produção material da vida. Não pode ser preterida, como acentua Henri Lefebvre, a relação entre espaço e tempo, visto que "cada um [espaço e tempo] se representa no outro e só se representa através desse outro. [...] O intelecto e o discurso separam o espaço do tempo e o tempo do espaço, porém os

\footnotetext{
${ }^{1}$ MARTINS, José de Souza. A sociedade vista do abismo: novos estudos sobre exclusão, pobreza e classes sociais. Petrópoles: Vozes, 2002, pp.34-35.

${ }^{2}$ Cf. LEFEBVRE, Henri. La presencia y la ausencia: contribuición a la teoria de las representaciones. (Trad. Espanhola de Óscar Barahona e Uxoa Doyhamboure). México: Fondo de Cultura Económica, 1983, p.37.
} 
inter-relaciona para representá-los um no e pelo outro."3 As representações da sociabilidade e da produção material da vida demandam, portanto, um apontamento do espaço-tempo de onde se fala, bem como de quem fala, sobre o que fala e para quem se fala. Os apontamentos que podem ser feitos quando se estuda uma realidade específica, como é o nosso caso, têm limitações espaço-temporais óbvias, mas não deixam, por isso, de serem importantes na compreensão do todo.

Estas considerações que vão sendo feitas evidenciam, desde já, uma problematização do referencial teórico-metodológico adotado. Certamente, as duas principais considerações a serem feitas neste sentido são a restrição local do estudo e seu albergamento no tempo presente - tenta-se compreender uma determinada realidade no seio de sua complexidade, simultaneamente ao modo como vai sendo. Quanto à dimensão local que assume nossa abordagem, esta tenta ser uma visão alternativa, contra-hegemônica ao processo de mundialização em curso, uma valorização da diversidade e das diferenças (o reconhecimento da complexidade da relação global/local quando o poder econômico globaliza localismos), fundada na vivência cotidiana dos moradores de um bairro pobre. Advertimos, porém, que esta condição (pobreza) não confere, automaticamente, a tais sujeitos um protagonismo histórico, uma virtude maior ou um modo de reflexão restrito ao econômico, mas justifica-se fundamentalmente por ser vivência sócio-cultural comum à maioria dos brasileiros e dos latino-americanos. Toda essa sorte de questões, no entanto, é tratada no tempo presente, por pessoas presentes, inseridas em uma realidade inconclusa e em transformação; as representações se interpõem, conforme assinala Lefebvre, entre a presença e a ausência pela mediação material do vivido - a presença "sempre se dá em uma forma, e, sem embargo, tomada separadamente, é ôca, portanto ausência. Tomado separado o conteúdo é amorfo, portanto ausente. Forma e conteúdo separados são fugas da presença."4

Conforme vai se evidenciando, nosso estudo, não só pelo enfoque, pela postura que se pretende transdisciplinar (indo além da área jurídica), mas também

\footnotetext{
${ }^{3}$ Idem, ibidem, p.50. O trecho citado foi livremente traduzido do espanhol, da obra referida, onde se lê: "Cada uno se representa en el otro y sólo se representa a través de se otro. [...] El intelecto y el discurso separam el espacio del tiempo y el tiempo del espacio, pero los cruzam para representarlos uno en y por el otro."

${ }^{4}$ Ibidem, pp. 255-256. Trecho traduzido livremente do espanhol, na obra referida: "La presencia? Siempre se da en una forma, y sin embargo la forma, tomada separadamente, es hueca, por lo tanto ausencia. Tomado por separado el contenido es informe, por lo tanto ausente. Forma y contenido separados son fugas de la presencia."
} 
pela inserção de sujeitos raramente ouvidos pelos pesquisadores da área jurídica e pela adoção (igualmente incomum em direito) das fontes orais, demandou uma reflexão teórico-metodológica. O estudo, assim, seguiu as formulações da História Oral, já que o trabalho carecia de fundamentos para a produção e interpretação das fontes orais que possibilitassem uma leitura das representações sociais. Possibilitando uma atuação de pesquisa de campo, inserindo personagens tradicionalmente alijados não só da história oficial como também do direito oficial, a História Oral não é apenas uma técnica para a realização de entrevistas, mas, além disso, propõe uma autocrítica constante sobre a ação do pesquisador, as relações intersubjetivas que se dão no ato da pesquisa, além de configurar uma possibilidade de inovação na pesquisa em sociologia e história do direito - indo além dos tradicionais estudos meramente bibliográficos ou jurisprudenciais - para uma ampla compreensão do fenômeno jurídico e suas fraturas.

A pesquisa das representações sociais dos trabalhadores acerca da justiça estatal, especificamente a justiça trabalhista, encontra nos subsídios teóricometodológicos da História Oral uma possibilidade de leitura do acesso à Justiça que a este não conceba somente em seu aspecto institucional (Poder Judiciário), mas também, e principalmente, em seus conteúdos axiológicos; no caso, nossa abordagem se concentra nos empecilhos sociais e culturais que se põem no acesso das camadas pobres à Justiça (em sentido axiológico), e como tais barreiras influenciam nas representações feitas acerca da justiça oficial e, em especial, da justiça trabalhista.

\section{ACESSO À JUSTIÇA TRABALHISTA NO BRASIL DA NOSSA ÉPOCA:}

A abordagem do acesso à justiça do trabalho, segundo uma perspectiva de totalidade, não pode se restringir, como temos afirmado, ao mero estabelecimento de uma relação processual, como se esta estivesse desvinculada de um processo histórico e não se encontrasse inter-relacionada aos vários conteúdos da vida social - político, econômico, cultural, sociológico, etc. Tal se dá porque, ao nos referirmos ao acesso à justiça do trabalho, não estamos nos referimos a um conjunto de normas autogenitoras que teriam se constituído anteriormente ao homem ou à revelia deste; estamos, sim, nos referindo a construções humanas - produtos 
complexos que não se resumem a este ou aquele aspecto restritamente, mas envolvem todas as contradições decorrentes de um processo histórico mais amplo. Obviamente, o movimento do acesso à justiça não se cinge a esta segmentação imposta pela divisão social do trabalho - a justiça trabalhista -; esta constitui um dos pontos de onde se pode partir (principalmente se se admite uma centralidade do mundo do trabalho) para o conhecimento dos processos sempre mais complexos e amplos, desencadeados pela totalidade da justiça do Estado. Importa afirmar que a justiça do trabalho é um dos pontos privilegiados para atingirmos outros, mas que não podemos entendê-la senão em sua relação com as outras divisões do Judiciário estatal. Afirmamos ser a justiça do trabalho um dos referenciais privilegiados porque não é raro que se tenha - hipoteticamente, quando se aborda o acesso à justiça estatal - a impressão de ser esta a seção da justiça (mesmo com o freqüente acesso involuntário à justiça penal) onde o acesso é mais efetivo. Embora essa representação pareça configurar uma visão isolada, o próprio perfil dos integrantes da justiça trabalhista, a mitigação do formalismo (comum na área cível), o caráter da não-contenciosidade, contribuem para a impressão de um acesso mais efetivo a esta área judicial.

Reportar ao acesso das pessoas à Justiça é, não só questionar como tem sido as condições para que hajam petições pleiteando direitos legalmente garantidos, mas também inquirir sobre como tem sido o desenrolar das relações processuais estabelecidas, e quais os reais efeitos decorrentes da decisão proferida em juízo; além, é claro, de observar se os conteúdos legislados têm sido efetivados (ou se de sua inefetividade têm derivado juridicidades comunitárias, alternativas à estatal), como tem sido essa potencial efetivação, e se a partir dela, as pessoas têm buscado orientar novas práticas e ampliar o alcance das garantias legais.

Filosoficamente, o movimento por acesso à justiça, ainda em uma perspectiva do instituído oficial, conforme afirma Mauro Cappelletti, "[...] expressou uma potente reação contra uma impostação dogmático-formalista que pretendia identificar o fenômeno jurídico exclusivamente ao complexo da norma, essencialmente de derivação estatal, de um determinado país."

${ }^{5}$ CAPPELLETTI, Mauro. O acesso à justiça e a função do jurista em nossa época.. In XIII Conferência Nacional da Ordem dos Advogados do Brasil, Revista de Processo, n. 61, Atualidades internacionais, Belo Horizonte, 1990, p. 144, 
Conseqüentemente, tratar do acesso à justiça implica admitir principalmente considerando-se nossa realidade social, marcada por um alijamento das massas populares da efetiva participação nos direitos legislados, e por uma conseqüente perda de legitimidade das instituições oficiais - uma série de obstáculos para que se chegue ao mínimo de uma participação em um acesso ainda formal, que se dá quando do estabelecimento da relação processual. Tais obstáculos não se restringem ao aspecto econômico (de todos o mais evidente ou o que mais toma a atenção da nossa sociedade capitalista), mas encontram desdobramentos nos chamados obstáculos sociais e culturais ao acesso à Justiça, dos quais se ocupou, em seus estudos ${ }^{6}$, Boaventura de Sousa Santos. Afirma-nos este autor que os cidadãos das camadas mais pobres tendem a conhecer pior os seus direitos legislados e, conseqüentemente, a ter dificuldades em reconhecer determinado problema como jurídico, podendo ignorar os direitos em questão ou as possibilidades de reparação jurídica. Além disso, entre os obstáculos culturais podemos, segundo Boaventura, incluir as anteriores experiências frustrantes com a justiça estatal, o medo de represálias decorrentes da ida a juízo, além de ser menos provável que uma pessoa das camadas sociais mais desfavorecidas conheça um advogado ou tenha amigos que conheçam, menos provável ainda é que saibam onde procurar atendimento judiciário, pois, geralmente, essas pessoas moram em zonas da cidade (ou até mesmo do campo) distantes de onde se localizam os escritórios de advocacia e os prédios da justiça. ${ }^{7}$

$\mathrm{O}$ acesso à justiça do trabalho abrange, inclusive, o papel dos sindicatos e das empresas na mediação que se estabelece entre o trabalhador e a justiça trabalhista; nesse percurso incluem-se, como produtos dessas relações, as chamadas Comissões de Conciliação Prévia (CCP's) e os ultimamente autodenominados "tribunais" de arbitragem. Além disso, devemos considerar o fato de que devido à política neoliberal desenvolvida em nosso país na última década, marcada pela recessão e quebra de várias empresas, corte de gastos em várias outras, somou-se um vasto número de desempregados, aumentando o número de

\footnotetext{
${ }^{6}$ Cf. especialmente a obra 0 discurso e o poder: ensaio sobre a sociologia da retórica jurídica. Porto Alegre: Fabris, 1988, síntese de uma pesquisa já clássica, realizada por Boaventura de S. Santos na favela do Jacarezinho, na cidade do Rio de Janeiro, na década de 1970.

${ }^{7}$ Cf. SANTOS, Boaventura de Sousa. A sociologia dos tribunais e a administração da justiça. In: Pela mão de Alice: o social e o político na pós-modernidade. São Paulo: Cortez, 1995, p. 170.
} 
cerca de quatro milhões de pessoas (em 1996) para quase treze milhões em $2001 .^{8}$ Tais observações interessam no contexto do acesso das pessoas à justiça do trabalho, porque dão-nos a dimensão de que não são só os empregados os interessados em ter os direitos legislados observados em seu cotidiano. Além desse aspecto, há um outro mais estreitamente ligado ao acesso à justiça trabalhista. Uma grande parcela dos trabalhadores que põem fim aos seus contratos de trabalhos nos mal-denominados "tribunais" de arbitragem ${ }^{9}$, nem tem conhecimento de que esteja em uma sessão de arbitragem (a própria organização do espaço físico, usando inclusive dos símbolos oficiais da justiça estatal, a vestimenta e o comportamento dos árbitros como se juízes fossem) ou sequer foi consultada sobre a conveniência ou não de determinado árbitro, além de serem os valores (oferecidos pelas empresas e acertados ao final) sempre menores do que os pleiteados. Os "tribunais" de arbitragem alegam ser desnecessária a informação de que irá o trabalhador acertar as contas em um "tribunal" de arbitragem, pois tal medida já fora anteriormente acertada em convenção coletiva dos sindicatos. Além do desconhecimento da organização judiciária a induzir o trabalhador, fazendo este erroneamente supor que esteja na justiça trabalhista, após firmado o laudo arbitral, não pode mais o trabalhador propor qualquer recurso ou ingressar na justiça para modificá-lo. $^{10}$

Conforme mencionado na reportagem citada (nota 08), vários advogados defendem ser impensável esse tipo de resolução de conflitos trabalhistas nesses "tribunais" de arbitragem, pelo simples fato de que tais órgãos encontram-se, por lei, restritos à apreciação de direitos legalmente considerados "disponíveis", sendo ainda mais absurdo falar-se em rescisão do contrato de trabalho em um tal contexto. Há, porém, outra categoria que afirma serem estes direitos trabalhistas suscetíveis de serem transformados em patrimônio e, assim, serem levados à arbitragem.

\footnotetext{
${ }^{8}$ Cf. Pesquisa do Instituto Datafolha, publicada no jornal FOLHA DE SÃO PAULO, Caderno especial Trabalho, p. 02, São Paulo, 24. mar. 2002.

${ }^{9}$ A Lei n. 9.307/96 criou o instituto da arbitragem para a solução de impasses entre pessoas físicas e empresas em que estiverem envolvidos direitos disponíveis, não sendo necessário para ser um árbitro de qualquer formação jurídica, exigindo-se apenas que as partes acordem quanto à escolha deste. Os "tribunais" de arbitragem constituem um uso nocivo da lei da arbitragem que, aproveitando-se do crescente desemprego e da desinformação dos trabalhadores, viu nas rescisões trabalhistas um negócio lucrativo.

${ }^{10}$ Cf. ROLLI, Cláudia; FERNANDES, Fátima. Justiça privada é cilada para trabalhadores. FOLHA DE SÃO PAULO, Caderno Dinheiro, São Paulo, 27. mai. 2002, p. B.1.
} 
Fica evidente a mutilação que procedimentos dessa natureza podem causar às garantias legais asseguradas aos trabalhadores, principalmente se considerarmos que existem cerca de 150 câmaras de arbitragem pelo país, responsáveis por aproximadamente 390 mil acordos trabalhistas por ano, uma média de dez por dia; representando esses números, $22 \%$ das reclamações feitas na justiça do trabalho (1,74 milhão, em 2001). ${ }^{11}$

Quanto às Comissões de Conciliação Prévia (CCP's) - estima-se que existam atualmente no Brasil cerca de 1.100, sendo que cada uma realiza em média dez acordos por dia, resultariam em 2,9 milhões de conciliações ao longo de um ano -, a situação é tão insustentável que tem sido defendida a extinção das muitas onde foram observadas irregularidades. Cumpre ressaltar que tais comissões são formadas por sindicatos e empresas, o que torna ainda mais duvidosa a possibilidade de o trabalhador ver as garantias legais observadas. Entre aqueles que operam no âmbito da justiça do trabalho há a posição de que, persistindo as ilegalidades cometidas por essas comissões, deverão elas ser extintas. ${ }^{12}$

Observa-se, através dessas considerações, em ambos os casos - tanto dos "tribunais" de arbitragem quanto das Comissões de Conciliação Prévia - o papel central ocupado pelos sindicatos na polêmica. No primeiro caso, os diretores dos "tribunais" alegam que nada tem a ser avisado aos trabalhadores quando estes ali aparecem, tudo já ficara acertado na convenção coletiva e o trabalhador deve estar ciente desse acordo; no segundo caso, das CCJ's, as irregularidades resultam da conjunta ação de empresas e sindicatos, voltando-se estes contra os próprios trabalhadores que, em tese, representam. A escusa dos "tribunais" de arbitragem cai por terra se considerarmos que, dos trabalhadores com carteira assinada, apenas $35 \%$ são sindicalizados. ${ }^{13}$ Esse baixo percentual de adesão pode, em parte, ser explicado por ações como as dos sindicatos nas CCJ's.

Embora a pesquisa do Instituto Datafolha, mencionada anteriormente, mostre que $83 \%$ dos trabalhadores entrevistados considera bastante importante ser afiliado a um sindicato, poucos o fazem. A perda de legitimidade dos sindicatos

${ }^{11}$ Cf. Idem, ibidem.

${ }^{12}$ Cf. SOFIA, Juliana. Proposta contra irregularidades em CPP recebem crítica. FOLHA DE SÃO PAULO, Caderno Dinheiro, São Paulo, 06 jun. 2002, p. B. 13.

13 Cf. a Pesquisa do Instituto Datafolha, citada na nota n. 03. 
pode, conforme afirma o cientista político Leôncio Martins, ${ }^{14}$ advir do fato de que estes perderam sua bandeira de luta após o fim da ditadura. Nos tempos recentes, o sindicato tenta levantar outras questões, como a cidadania, a denúncia da discriminação racial, a perseguição aos imigrantes etc. "isso poderia permitir que o sindicato tivesse um outro papel no mundo contemporâneo." Segundo Martins, os sindicatos têm muitas vantagens decorrentes de suas quatro fontes de renda contribuições sindicais, assistenciais e confederativas, além das mensalidades -, e não cumprem seu papel, beneficiando apenas um pequeno grupo de associados. Além disso, acentua o professor, os sindicatos não têm interesse em aumentar bastante o número de filiados, fato que contribuiria para estourar o orçamento; "como têm renda garantida, é melhor que não haja grande adesão de trabalhadores [...] a contribuição [sindical] sustenta um bando de sindicatos que são fantasmas, e a unicidade não permite a concorrência."15

Não queremos aqui desqualificar a atuação dos sindicatos, deshistoricizando suas conquistas importantes no decorrer da última metade do século XX. Apenas pretendemos mostrar a importância das organizações sindicais quando se aborda o acesso à justiça do trabalho. As vicissitudes observadas em vários sindicatos e órgãos de conciliação, não negamos (rechaçamos uma concepção monista), certamente podem ser observadas na justiça estatal, com as claras variações de estruturas organizacionais e gradações de vícios. Embora a justiça do trabalho encontre limitações várias e a lei trabalhista estatal não consiga jamais dar conta da complexidade da realidade social, os problemas tendem (pelo caráter público) a ser mitigados na justiça oficial, se tomarmos como referências os "tribunais" de arbitragem e as Comissões de Conciliação Prévia. Entretanto, os problemas do desconhecimento dos direitos legislados, a precariedade do atendimento advocatício (muitas vezes feito por profissionais que acumulam cargas de trabalho sobre-humanas), a atitude hermenêutica formalista dos juízes, persistem. O que diferencia a "justiça privada" da justiça estatal fica sendo, conforme o imperativo da velocidade da lógica mercadológica, que naquela arrisca-se a ter garantias violadas em nome da celeridade, nesta a demora torna insignificantes as

${ }^{14}$ Cf. Entrevista de Leôncio Martins ao jornal FOLHA DE SÃO PAULO, Caderno Dinheiro, São Paulo, 01 dez. 2002, p. B.11.

${ }^{15}$ Cf. a matéria jornalística referida na nota anterior. 
possíveis indenizações a serem recebidas (considerando-se os gastos com 0 processo).

Há dez anos existem no Brasil 1.109 Varas do Trabalho, número que se manteve inalterado nesta década. Em 1992, foram recebidos, em todo o país, 1.799.992 processos trabalhistas, cabendo 1.623 processos por Vara; em 2000, foram recebidos 2.272.760 processos, uma média de 2.050 processos por Vara. Isso quando a lei só admite sejam recebidos anualmente em cada Vara até o máximo de 1.500 processos. $^{16}$

Considerando-se o acesso à Justiça como a mais elementar garantia para que se possa, minimamente, pleitear uma efetivação dos direitos legislados, e que o trabalhador (condição indissociável de outras áreas da justiça oficial) talvez nem saiba da justiça do trabalho, talvez nem saiba de muitos dos direitos legislados, percebemos que antes de ser estabelecida a relação processual, há uma série de obstáculos (antes mesmo do aspecto econômico) que fazem do pleno acesso à Justiça uma quimera. Aliás, a abordagem do acesso à justiça do trabalho é, indiretamente, também um questionamento do direito ao trabalho - a instituição judicial e suas decisões não deixam de interferir (positiva ou negativamente) em um contexto em que a maioria dos brasileiros, em nome da sobrevivência, ocupa funções informais (ilegais em relação do direito estatal) que lhes garanta a sobrevivência.

\section{VILA GOSUEN: A JUSTIÇA VISTA PELOS MORADORES DA PERIFERIA}

O acesso ao trabalho na Vila Gosuen - pequeno bairro da região norte de Franca onde vivem 625 moradores, formado por ocupação irregular (de acordo com o direito estatal) de terras (no final da década de 1950) e pela população de uma favela, transferida para o local pela municipalidade em 1984, em um projeto de desfavelamento - não pode, contudo ser compreendido sem a consideração de uma

${ }^{16}$ Cf. FILHO, Hugo C. M. Acesso à justiça do trabalho, FOLHA DE SÃo PAULO, Tendências/debates, São Paulo, 26 jun. 2002 , p. A3. 
situação de preconceito $^{17}$ que perpassa os vários setores da vida da localidade: o estigma pelo simples fato de morar na Vila Gosuen. Seja empregada qualquer das designações pejorativas com que a imprensa e a sociedade locais se referem ao bairro - Puxa-faca, Vila Gosuen, favela -, o preconceito pelo simples fato de as pessoas morarem no lugar é algo, entre os sujeitos pesquisados, incontroverso. Não só o preconceito atinge este ou aquele aspecto da vida, mas estende-se a todos; não apenas se restringe às crianças discriminadas na escola (a Vila Gosuen não tem escola e as pessoas têm de freqüentar a escola pública dos bairros vizinhos), aos trabalhadores cujos colegas de serviço se negam a visitar suas casas por se situarem onde se situam, àqueles que procuram calçados para costurar ou qualquer outro emprego, aos que desejam vender as casas onde moram, aos que procuram advogados, interferindo até mesmo nas relações afetivas. Essas afirmações podem ser verificadas nas falas de vários moradores:

"É, não, aqui é meio discriminado. [...] mesmo os rapaiz que mora aqui, se falá que mora aqui, num pega serviço fácil não. Aqui é discriminado. Mas, eu dô razão, só tem baguncento e vagabundo desse lado aqui, então...."18

"Quando fala que mora aqui na Vila Gosuen - cê vai fazê um cadastro, cê vai fazê arguma ficha, cê vai fazê quarqué coisa -, cê fala que mora na Vila Gosuen, já mistura tudo! [...] Puxa-faca, né? Eles conhecem muito por Puxa-faca, né. Falô que é Vila Gosuen, [a pessoa] fala 'não, é lá no Puxa-faca!'”19

"pra todo mundo, aqui é igual, porque pra fora, aqui todo mundo é igual - aqui todo mundo é vagabundo. Vila Gosuen, nossa senhora! [...] No meu serviço [...] lá é uma empresa [...] muito exigente, né? Falei "ih, só falta eles num querê me pegá porque eu moro na Gosuen [...] porque tem discriminação, tem discriminação, bastante?"20

${ }^{17}$ Conforme Agnes Heller - O cotidiano e a história. (Trad. de Carlos Nelson Coutinho e Leandro Konder). 4.ed. Rio de Janeiro: Paz e Terra, 1992 -, para quem "o preconceito é um tipo particular de juízo provisório" (p.45), alicerçado na vida cotidiana, marcado pela ultrageneralização e pela unidade imediata de pensamento e ação, todas as pessoas, em certa medida e sob alguns aspectos, têm preconceitos; a pessoa "predisposta ao preconceito rotula o que tem diante de si e o enquadra numa estereotipia de grupo. Ao fazer isso, habitualmente passa por cima das propriedades do indivíduo que não coincidem com as do grupo" (p.57).

18 Entrevista com Ivo (52 anos de idade, borracheiro autônomo, casado, estudou até a $2^{\mathrm{a}}$ série do primário), realizada em 13.09.2003. OBS: Os nomes dos entrevistados foram mudados para resguardar-lhes a privacidade.

19 Entrevista com Rosa, (52 anos, solteira, 7 filhos, empregada doméstica há 36 anos na mesma casa), realizada em 23.08.2003.

${ }^{20}$ Entrevista com Ester, (40 anos, 1ำ grau completo, casada, mãe de 3 filhos [além de uma sobrinha adotada], sapateira), realizada em 28.02.2004. 
Por ser tão forte o preconceito, há moradores que omitem, muitas vezes, onde moram, fornecendo endereços de moradores de bairros vizinhos como sendo seus. ${ }^{21}$ Há preconceito entre os próprios moradores, segmentações dentro do próprio espaço do bairro, principalmente em relação às pessoas provindas da antiga Favela da Caixa D’Água (um projeto de desfavelamento pôs termo à favela em 1984, depois de cerca de 50 anos de vivência de várias famílias na localidade). Referindo-se a estas, uma senhora moradora da área mais antiga da Vila Gosuen, declarou: "eles não têm educação, gritam, falam besteira! Deviam ser levados para a fazenda - eles são muito porcos!" As pessoas do restante do bairro acentuam sempre "o povo da favela", mal tendo a compreensão, como se percebe da fala da moradora Ester (remanescente da favela), que as pessoas do restante tratam todos dali iguais - iguais em vadiagem, iguais em tráfico de drogas, iguais em ilegalidade.

O preconceito encontra aval mesmo em pessoas que o reconhecem, como Ivo, que afirma dar "razão [a quem discrimina], só tem baguncento e vagabundo desse lado aqui, então..." O próprio morador cuida de avalizar o preconceito do qual também é vítima, encontrando-se seus argumentos fundados em valores de conservação, os valores da "ordem" que os "vagabundos" emperram. São esses componentes conservadores e de reprodução de preconceitos (marcados pela ideologia e pela alienação) que fundamentam os argumentos negadores da possibilidade do cotidiano ser praxis. ${ }^{22}$ Mas, conforme Henri Lefebvre, a superação do cotidiano se dá a partir de seus próprios elementos, a partir da própria

realizada em 28.02.2004.

21 Em várias partes pudemos observar como o preconceito encontra-se disseminado e enraizado até mesmo nas instituições da cidade: como exemplo, podemos citar o ocorrido no Projeto de lei 16/2002, que autorizou a doação de uma área na Vila Gosuen (antigo pátio de veículos apreendidos) para a construção de prédios residenciais populares; nesse projeto, usou-se para localizar a área, inicialmente, o nome do bairro "Vila Gosuen", mas a Comissão de Avaliações passou textualmente a escrever "a área entre a Vila Santa Terezinha e o Parque D. Pedro I". O vereador Rubens Facirolli, contudo, à fl.45 do projeto de lei, propôs emenda, que foi aprovada, modificando a localização da área de "Vila Gosuen" para "entre a Vila Santa Terezinha e o Parque D. Pedro I"., passando em seguida para apenas "Parque D. Pedro I". A área continua situada na Vila Gosuen, mas este deve ser um nome muito feio, um tabu, que não pode ser expresso de modo algum.

${ }^{22}$ Adotamos a formulação da praxis, neste texto compreendida como praxis revolucionária, elaborada por Henri Lefebvre a partir de sua leitura de Marx: "A praxis existe em três níveis: o repetitivo, o inovador nos dois pólos e, entre os dois, o mimético. A praxis repetitiva recomeça os mesmo gestos, os mesmo atos em ciclos determinados. A praxis mimética segue modelos; pode suceder que, imitando, ela chegue a criar, mas sem saber como nem por quê; mais freqüentemente ela imita sem criar. Quanto à praxis inventiva e criadora, ela atinge seu nível mais elevado na atividade revolucionária. Esta atividade pode ser ser exercida tão bem no campo do conhecimento e da cultura (a ideologia), como no da ação política. Contudo, a ação política concentra e condensa tôdas as mudanças parciais em um fenômeno total: a revolução que transforma o modo de produção, as relações de produção e de propriedade, as idéias e as instituições, a maneira de viver. A praxis revolucionária introduz descontinuidades no processo global sócio-histórico." in: LEFEBVRE, Henri. Sociologia de Marx. (Trad. de Carlos Roberto A. Dias). Rio de Janeiro/São Paulo: Forense, 1968, p.37. 
cotidianidade - "o possível, o virtual, o futuro, não se representam senão através do imaginário. Trabalhadas, elaboradas essas representações se tornam utopias afirmativas ou negativas". 23

Quase sempre relacionado à esfera do trabalho, o preconceito é bastante nítido em relação a uns poucos moradores do bairro que recebem segurodesemprego; este benefício é tido, no entanto, como um incentivo para que as pessoas não voltem a procurar um serviço; como pode ser visto nas palavras de Ivo, um dos nossos entrevistados:

"Uai, mas vai recebê se não tá trabaiano, uai?! O que eu acho errado é isso aí, moço, mas quem é eu pra cunsertá um trem desse?! [...] Cê trabaiô? Boa. Cumbinô co'home quanto que é por dia, ou por mêiz... Cê recebeu aquilo, é aquilo, uai! Agora, cê trabaia seis mêis aí, oh... desses seis mêiz, o seguro-desmprego, cê vai ficá trêis mêiz parado. Mesmo que aparecê ôto serviço pro'cê, cê num vai. Cê num pode registrá que cê perde aquela... aquele direito seu. Aquele direito?! Aquele roubo que eles tão te dando. Então, cê vai trabaiá? [...] Pra quê? Desse jeito aí, oh."24

Freqüentemente, e ainda adotando a categoria trabalho, os sujeitos da pesquisa fazem questão de esclarecer que a maioria dos moradores da Vila Gosuen "é mais trabaiadô que os prayboy daí! Os prayboy só fica assim assim na máquina ou assim assim na caneta; agora, põe um deles pra pegá no pesado, pra vê se aprende abaná um café numa semana!"25 Ratificando que "tem gente que num trabalha, só vive de cesta básica... [...] eu creio que acomoda; eu sei lá..."26 e que

"[...] Eu mesmo, nós aqui... eu saio cedo, meu marido sai cedo (às vezes fica quinze dia fora, né?), meu filho levanta cedo, vai trabalhá na loja lá [...] mas tem outros aqui que é acomodado demais, sabe, acomodado demais! Então é onde que começa ganhá dinheiro

23 LEFEBVRE, Henri. La presencia y la ausencia: contribuición a la teoria de las representaciones. Cidade do México: Fondo de Cultura Económica do México, 1983, p.63. Trecho livremente traduzido do espanhol: "[...] lo posible, lo virtual, lo futuro no se representan sino a través de lo imaginario. Trabajadas, elaboradas, esas representaciones se vuelvén utopias afirmativas o negativas."

${ }^{24}$ Entrevista com Ivo, realizada em 13.09.2003.

${ }^{25}$ Entrevista realizada em 14.02.2004 com Ari (cerca de 40 anos, $2^{\circ}$ grau completo, separado, pai de 5 filhos, dependente alcoólico e químico, desempregado), morador de um barraco que aproveita o muro de uma das passagens como parede. Conta ter servido ao Exército em "Corumbá, na 17르 base", teve duas fabriquetas de calçados e, após a frustração de seu casamento, perdeu tudo o que tinha, apenas deixando uma casa para a mulher e os filhos, entregando-se ao vício das drogas e da bebida.

${ }^{26}$ Entrevista conjunta realizada com Juvenal Filho (58 anos, $2^{2}$ série, casado, pedreiro, casado) e sua esposa Hilda (49 anos, $1^{\text {a }}$ série, desempregada [doméstica]), em 17.03.2004. 
fácil, porque acha que envolvendo com outras coisa ganha dinheiro fácil. Então é onde que acomoda..."27

O nível de qualificação dos trabalhadores da Vila Gosuen, a taxa de participação dos adultos na força de trabalho e o poder de barganha destes, a produtividade média das funções (quase sempre não chegam a configurar o que formalmente se designa como "emprego") em que estes estão inseridos, a qualidade potencial da força de trabalho, e, principalmente, o preconceito por habitarem uma área difundida como criminógena, contribuem para que o trabalho dentre os vários outros fatores da vida (moradia, saúde, educação, lazer) seja também precarizado e não ofereça a mínima diginidade - "a dignidade da gente é pegá o dinheiro da gente e ir no supermercado e comprá o que comer."28

Em uma realidade nacional ${ }^{29}$ em que $46 \%$ dos trabalhadores nunca tiveram registro em carteira profissional, 54\% não recebem 13ำ salário, 55\% não recebem férias remuneradas, e $81 \%$ não têm plano de saúde, a concepção de direitos trabalhistas e de justiça do trabalho passa a reproduzir a lógica da exploração, como nas palavras de Ivo:

"Eu tomei conta de uma fazenda 18 anos. [...] Ele [o patrão] tinha que pagá [na rescisão] $13^{\circ}$... saiu aquela fulia de $14^{\circ}$ salário... num sei o quê, tempo de serviço... frescura da lei, aí, oh! Ele fez o cheque; eu num quis o cheque, não! [...] Não, que já tava tudo pago... já tinha pagado. É, num sei como é que fala... rescisão de serviço, num sei o quê, tá tudo certin, dado baixa na carteira... [...] Não, eu acho... não. Cara vai trabaiá, se ele ganha por... cê cumbinô 15 conto por dia, é 15 conto por dia, uai; cê trabaiô 1 ano, 2 ano, então, cê tem direito de 30 dia de descanso... até aí, tudo bem!”30

O desconhecimento dos direitos e o entendimento de que a "honestidade" confundida com a reprodução da exploração - não deve ceder às "frescuras da lei", implica representações da justiça estatal como algo alheio, dispensável, muitas vezes responsável por incentivar uma vida acomodada - a "vadiagem" - a que não reconhecem dignidade. Aliás, mesmo que a maioria da população esteja desempregada ou se sustente em ocupações informais - foram ouvidas 270

\footnotetext{
${ }^{27}$ Entrevista com Ester, realizada em 28.02.2004.

${ }^{28}$ Entrevista com Juvenal Filho, realizada em 17.03.2004.

${ }^{29}$ Conforme se observa da pesquisa realizada pelo Instituto Datafolha, publicada no jornal FOLHA DE SÃo PAULO, Caderno Especial - Folha Trabalho, 24. mar. de 2002.
} 
pessoas, das quais 62 de declaram "desempregadas", 20 aposentadas e 188 ocupam 46 diferentes funções, quase todas tidas como informais -, o trabalho não deixa de assumir uma centralidade não só em relação às situações de preconceito mencionadas, mas também entre os elementos capazes de conferir dignidade às pessoas. Importante enfatizar que, mesmo havendo moradores do bairro envolvidos com as atividades de tráfico de entorpecentes, quando se "ganha dinheiro fácil" (conforme uma de nossas entrevistadas), o critério para julgá-las é sempre o trabalho. Este, porém, é entendido, na maioria das vezes - como na frase de uma das nossas entrevistadas, anteriormente mencionada neste texto -, apenas como um meio para se comprar produtos para o atendimento das necessidades radicais ${ }^{31}$ ou daquelas necessidades criadas pelo consumismo. O trabalho não é, para os sujeitos pesquisados, um conteúdo de emancipação, mas apenas um meio de garantir a sobrevivência.

De alguma forma, o capital ainda necessita do trabalho para se reproduzir. A aparente criação de uma multidão de "descartáveis"33 é, em certa medida, uma falácia:

"Os mercados de trabalho e financeiro parecem no entanto conviver de forma conflituosa: o que é bom para um parece ruim para o outro e reciprocamente. De fato, as relações entre eles são complexas. As finanças são pagas pela mais-valia, mas podem permitir a produção de mais-valia. [...] o dinheiro por si só não produz dinheiro, sem a intervenção do trabalho, e se parece produzi-lo no setor financeiro, também nesse caso ele vem do trabalho, ainda que mediado por múltiplas vias e por mecanismo dificilmente perceptíveis."34

E, mesmo que não concordemos com a forma violenta do seu desenvolvimento, mesmo a "vida fácil" - as atividades desenvolvidas no tráfico de

${ }^{30}$ Entrevista com Ivo, realizada em 13.09.2003.

31 Agnes Heller entende por necessidades radicais, "todos os carecimentos nascidos na sociedade capitalista, em conseqüência do desenvolvimento da sociedade civil, mas que não podem ser satisfeitos dentro dos limites dessa sociedade. [...] os carecimentos radicais são fatores de superação da sociedade capitalista." Cf. HELLER, Agnes. Para mudar a vida: felicidade, liberdade e democracia. (Trad. de Carlos Nelson Coutinho). [Entrevista concedida a Ferdianndo Adornato]. São Paulo: Brasiliense, 1982, p.133.

${ }^{33}$ Expressão empregada por José de Souza Martins, quando este se referiu ao fato de que o discurso que se sustenta na díade exclusão/inclusão é um discurso dos "incluídos" e, conseqüentemente, de caráter conservador. Segundo o sociólogo, a "descartabilidade" é a forma extrema de coisifcação e alienação das pessoas; ao ser entendido como "excluído", o indivíduo passa a ser duplamente capturado pelo sistema: como consumidor dos "resíduos do sistema" e como participante de formas de protesto popular (incentivadas pela indústria cultural) que pleiteiam participação que apenas conformam a sociedade - como o tráfico, o roubo e a violência.

34 SALAMA, Pierre. Pobreza e exploração do trabalho na América Latina. São Paulo: Boitempo Editorial, 1999, p.55. 
drogas - é, mercadologicamente, conforme Pierre Salama, uma forma de trabalho (obviamente de trabalho alienado) - "os efeitos indiretos sobre o emprego e a criação de riquezas dependem ao mesmo tempo da parte investida nas despesas dos narcotraficantes, e do lugar em que esses investimentos são realizados" ${ }^{35}$

Embora os sujeitos pesquisados tenham, em várias oportunidades, se referido às atividades no tráfico de drogas, este não é reconhecido pelos moradores da localidade como uma forma de trabalho. As representações acerca deste não deixam de considerar as tentações da "vida fácil" e as "frescuras da lei". A justiça trabalhista é, de forma geral, algo distante, já que a maioria sequer tem registro em carteira de trabalho ou consegue atividades que se prolonguem no tempo. Isso não impede, todavia, que as conquistas trabalhistas, quando reconhecidas judicialmente ou apenas honradas, sejam vistas como fator de acomodação e de desestímulo ao trabalho, como é o caso do seguro-desemprego.

\section{CONSIDERAÇÕES FINAIS:}

A específica realidade estudada contribui não só para o conhecimento de como se dão não só as relações de trabalho em uma comunidade periférica de uma cidade industrial do interior de São Paulo, mas possibilita considerar que a precarização do acesso aos vários direitos humanos fundamentais é, também, o acesso a um trabalho que não emancipa nem sequer garante ter o mínimo para "ir ao supermercado comprar o que comer". Esta mera garantia de subsistência alimentar, porém, se atingida, garantiria apenas uma sobrevivência alienada em que a relação produtiva é entendida afastada de "sua função adequada de mediar humanamente as relações sujeito-objeto, entre homem e natureza, e tende, em lugar disso, a levar o indivíduo isolado e reificado a ser reabsorvido pela 'natureza'..36

${ }^{35}$ Idem, Ibidem, p.148.

${ }^{36}$ MÉSZÁROS, Istvan. Marx: a teoria da alienação. (Trad. de Waltensir Dutra). Rio de Janeiro: Zahar Editores, 1981, p.77. 
A centralidade do trabalho - em nossa argumentação compreendida como centralidade ontológica ${ }^{37}$, como a ação em que o homem, por meio do trabalho, transforma o mundo e também a si, perfazendo o seu processo de hominização acabou por ser amplamente confirmada na realidade específica da Vila Gosuen. Mesmo quando se referem a questões como o envolvimento com as drogas ou o preconceito acentuado em decorrência de tal situação, os sujeitos da pesquisa não deixam de se referir ao trabalho. Contudo, seria o trabalho - por eles, quase sempre entendido como trabalho alienado, restrito à sobrevivência - um ponto de ação capaz de uma praxis criadora e inventiva entre pessoas em sua maioria ocupadas em atividades informais (ilegais), trabalhadores da margem do sistema? Conforme a resposta de Ricardo Antunes ${ }^{38}$, da qual compartilhamos,

o eixo à resistência e o confronto à lógica do capital e à sociedade produtora de mercadorias, o centro desta ação encontra maior radicalidade quando se desenvolve e se amplia no interior das classes trabalhadoras, ainda que reconhecendo que esta empreitada é muito mais complexa e difícil que no passado, quando a sua fragmentação e heterogeneidade não tinham a intensidade encontrada no período recente.

É enganadora a solução que postula a inclusão dos desempregados ou dos sub-empregados no mercado de trabalho (expressão que por si só já carrega a perversa lógica da força de trabalho, posta como uma mercadoria em que aqueles que detém o capital podem atribuir-lhe o preço que quiserem, valor mísero ao qual o trabalhador acaba tendo de se sujeitar, muitas vezes); antes é necessário pensar soluções coletivas a partir da própria comunidade, considerando as possibilidades de desenvolvimento de estratégias locais de trabalho e produção. Embora o aspecto da existência ainda incipiente do tráfico de drogas na localidade estudada haja contra uma mobilização coletiva, há um conjunto de carências comuns e de não acessos que podem viabilizar a formação de sujeitos emancipatórios coletivos, "segmentos sociais [que] não têm mais nada a perder no universo da sociabilidade do capital. Sua subjetividade poderia ser, portanto, mais propensa à rebeldia. [...] a superação do capital somente poderá resultar de uma empreitada que aglutine e

\footnotetext{
37 Sobre as três principais concepções acerca da centralidade do trabalho - centralidade ontológica, centralidade do "mundo da vida" e fim da centralidade cotidiana do trabalho -, confira: LESSA, Sérgio. Centralidade do trabalho: qual centralidade?, Revista de Ciências Humanas, v.15, n.22, Florianópolis, UFSC/CFH, out. 1997, pp.153-164.

${ }^{38}$ ANTUNES, Ricardo. Adeus ao trabalho?: ensaio sobre as metamorfoses e a centralidade do mundo do trabalho. 4.ed. São Paulo: Cortez; Campinas/SP: Ed. UNICAMP, 1997, p.87.
} 
articule o conjunto dos segmentos que compreendem a classe-que-vive-dotrabalho."

A universidade pública, enquanto espaço ainda autônomo e público, por meio do incentivo às atividade de pesquisa e extensão, não pode se dissociar do saber comum (cuja centralidade se encontra no trabalho), da experiência cotidiana, cujo conhecimento é fundamental para a compreensão dos não-acessos (à justiça, ao trabalho, à vida, etc.) e o apontamento de possíveis soluções.

\section{REFERÊNCIAS BIBLIOGRÁFICAS:}

\section{LIVROS:}

ANTUNES, Ricardo. Adeus ao trabalho?: ensaio sobre as metamorfoses e a centralidade do mundo do trabalho. 4.ed. São Paulo: Cortez/ Campinas/SP: Ed. UNCAMP, 1997.

BENTIVOGLIO, Júlio César. Trajetória urbana de Franca: centro (1805-1995). (3ํ Conc. de Monografias da História dos bairros de Franca). Franca/SP: Fund. Cultural Mário de Andrade, 1996.

BOURDIN, Alain. A questão local. (Trad. de Orlando dos Reis). Rio de Janeiro: DP \& A, 2001.

CAPPELLETTI, Mauro; GARTH, B. Acesso à justiça. (Trad. Hellen G. Northfleet). Porto Alegre: Fabris, 1988.

CARVALHO, José Murilo de. A cidadania após a democratização. In:

Cidadania no Brasil: o longo caminho. Rio de Janeiro: Civilização Brasileira, 2001, pp.197-217 (cap. IV)

CHAHAD, José Paulo Zeetano; MENEZES-FILHO, Naércio A. (orgs.). Mercado de trabalho no Brasil: salário, emprego e desemprego numa era de grandes mudanças. São Paulo: LTr, 2002.

; PICCHETTI, Paulo (orgs.). Mercado de trabalho no Brasil: padrões de comportamento transformações institucionais. São Paulo: LTr, 2003.

CHAUÍ, Marilena. O que é ideologia. São Paulo: Abril Cultural/ Brasiliense, 1984.

DUSSEL, Enrique. Ética da libertação: na idade da globalização e da exclusão. (Trad. de Ephraim Ferreira Alves; Jaime A. Clasen; Lúcia M. E. Orth). Petrópolis/RJ: Vozes, 2000.

FALCÃO, Maria do Carmo; NETTO, José Paulo. Cotidiano: conhecimento e crítica. 2.ed. São Paulo: Cortez, 1989. 
FAUSTO, Ayrton; CERVINO, Ruben (orgs.). 0 trabalho e a rua: crianças e adolescentes no Brasil dos anos 80. 2.ed. São Paulo: Corterz, 1996.

FERREIRA, Marieta de Moraes (org.). História Oral e multidisciplinaridade. Rio de Janeiro: Diadorim Editora Ltda., 1994.

HELLER, Agnes. O cotidiano e a história. (Trad. de Carlos Nelson Coutinho e Leandro Konder). 4.ed. Rio de Janeiro: Paz e Terra, 1992.

Para mudar a vida: felicidade, liberdade e democracia. (Trad. de Carlos Nelson Coutinho). [Entrevista concedida a Ferdianndo Adornato]. São Paulo: Brasiliense, 1982,

KON, Anita. Desenvolvimento regional e trabalho no Brasil. São Paulo: Associação Brasileira de Estudos do Trabalho (ABET), 1998.

KONDER, Leandro. A questão da ideologia. São Paulo: Companhia das Letras, 2002.

KOSIK, Karel. Dialética do concreto. (Trad. Célia Neves e Alderico Toríbio). Rio de Janeiro: Paz e Terra, 1995.

LEFEBVRE, Henri. A revolução urbana. (Trad. Sérgio Martins). Belo Horizonte: UFMG, 1999.

Lógica formal/ lógica dialética. (Trad. Carlos Nelson Coutinho). 5.ed. Rio de Janeiro: Civilização Brasileira, 1991.

O direito à cidade. (Trad. Rubens Eduardo Frias). São Paulo: Editora Moraes, 1991 (b).

A vida cotidiana no mundo moderno. (Trad. de Alcides João de Barros). São Paulo: Ática, 1991(c).

La presencia y la ausencia: contribuición a la teoria de las representaciones. Cidade do México: Fondo de Cultura Económica do México, 1983.

LESSA, Sérgio. Centralidade do trabalho: qual centralidade?, Revista de Ciências Humanas, v.15, n.22, Florianópolis, UFSC/CFH, out. 1997, pp.153-164.

LYRA FILHO, Roberto. O que é direito. 10.ed. São Paulo: Brasiliense, 1990.

MARTINS, José de Souza. A sociedade vista do abismo: novos estudos sobre exclusão, pobreza e classes sociais. Petrópolis/RJ: Vozes, 2002.

A sociabilidade do homem simples. São Paulo: Hucitec, 2000.

MÉSZAROS, Istvan. Marx e a teoria da alienação. (Trad. Waltensei Dutra). Rio de Janeiro: Zahar, 1981.

ROSA, Maria Inês. Trabalho, subjetividade e poder. São Paulo: EDUSP/ Letras \& Letras, 1994. 
SALAMA, Pierre. Pobreza e exploração do trabalho na América Latina. São Paulo: Boitempo Editorial, 1999.

SANTOS, Boaventura de Sousa. Pela mão de Alice: o social e o político na pós-modernidade. São Paulo: Cortez, 1995.

O discurso e o poder: ensaio sobre a sociologia da retórica jurídica. Porto Alegre: Fabris, 1988.

SANTOS, Milton. Pobreza urbana. 2.ed. São Paulo: Hucitec, 1979.

SOUZA, Marcelo José L. Urbanização e desenvolvimento no Brasil atual. São Paulo: Ática, 1996.

THOMPSON, Paul. A voz do passado: história oral. (Trad. Lólio L. de Oliveira). Rio de Janeiro: Paz e Terra, 1992

VELLOSO, João Paulo dos Reis; ALBUQUERQUE, Roberto Cavalcanti (orgs.). Modernidade e pobreza. São Paulo: Nobel, 1994.

WESTPHAL, Márcia Faria et. al. Influência do trabalho terceirizado na indústria de calçados de Franca-SP, no desenvolvimento da criança trabalhadora. (Relatório de pesquisa). São Paulo: FUNDACENTRO/ NUPESE (Fac. de Saúde Pública-USP)/ Escola de Enfermagem-USP, 1994 a 1998.

WOLKMER, Antônio Carlos. Pluralismo jurídico: fundamentos de uma nova cultura no direito. 2.ed. São Paulo: Alfa-Ômega, 2001.

O terceiro mundo e a nova ordem internacional. São Paulo: Ática, 1989.

\section{FONTES ORAIS:}

Entrevista com Ivo (nome fictício) - 52 anos de idade, borracheiro autônomo, casado, estudou até a $2^{a}$ série do primário, morador da Vila Gosuen a cerca de 40 anos. Ent. realizada em 13.09.2003.

Entrevista com Rosa (nome fictício) - 52 anos, solteira, analfabeta, 7 filhos, empregada doméstica, reside na Vila Gosuen desde 22 de dezembro de 1984 (quando houve a transferência das famílias participantes do projeto de desfavelamento). Entrevista realizada em 23.08.2003.

Entrevista com Ester (nome fictício) - 40 anos, 1ำ grau completo, casada, mãe de 3 filhos [além de uma sobrinha adotada], sapateira (com carteira registrada), residente na Vila Gosuen desde 22.12.1984. Entrevista realizada em 28.02.2004.

Entrevista com Ari (nome fictício) - cerca de 40 anos, $2^{\circ}$ grau completo, separado, pai de 5 filhos, dependente alcoólico e químico, desempregado, morador de um barraco que aproveita o muro de uma das passagens da vila como parede, morador há pouco mais de um ano. Entrevista realizada em 14.02.2004 
Entrevista conjunta realizada com Juvenal Filho (nome fictício) - 58 anos, $2^{2}$ série, casado, pedreiro, casado - e sua esposa Hilda (nome fictício) - 49 anos, 1a série, desempregada [doméstica] -, ambos moradores da Vila Gosuen desde 22.12.1984. Entrevista realizada em 17.03.2004.

\section{FONTES ESCRITAS:}

FOLHA DE SÃO PAULO, Caderno especial - Trabalho -, p. 02, São Paulo, 24. mar. 2002.

ROLLI, Cláudia; FERNANDES, Fátima. "Justiça privada é cilada para trabalhadores". FOLHA DE SÃO PAULO, Caderno Dinheiro, São Paulo, 27 mai. 2002, p. B.1.

Entrevista de Leôncio Martins ao jornal FOLHA DE SÃO PAULO, Caderno Dinheiro, São Paulo, 01 dez. 2002, p. B.11. 